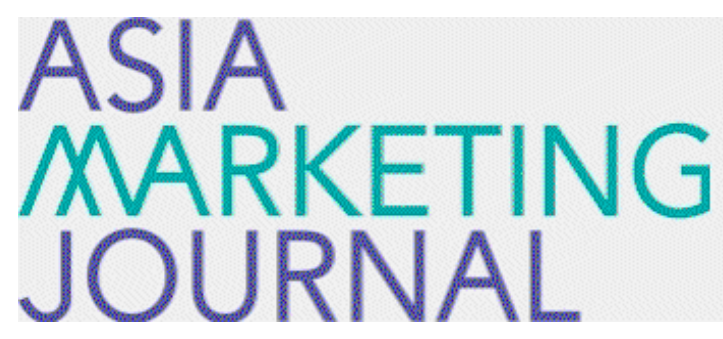

ASIA MARKETING JOURNAL

Volume 19 | Issue 3

Article 4

$10-31-2017$

\title{
Effects of Individual Difference on Organizational Difference: \\ Perceived Training Effectiveness Model for Organizational \\ Performance
}

Beenish Malik

Jahanvash Karim

Tayyaba Noreen

Han

Follow this and additional works at: https://amj.kma.re.kr/journal

Part of the Marketing Commons

\section{Recommended Citation}

Malik, Beenish; Karim, Jahanvash; Noreen, Tayyaba; and Han (2017) "Effects of Individual Difference on Organizational Difference: Perceived Training Effectiveness Model for Organizational Performance," Asia Marketing Journal: Vol. 19 : Iss. 3 , Article 4.

Available at: https://doi.org/10.15830/amj.2017.19.3.75

This Article is brought to you for free and open access by Asia Marketing Journal. It has been accepted for inclusion in Asia Marketing Journal by an authorized editor of Asia Marketing Journal. 


\title{
Effects of Individual Difference on Organizational Difference: Perceived Training Effectiveness Model for Organizational Performance
}

\author{
Beenish Malik* \\ Jahanvash Karim** \\ Tayyaba Noreen*** \\ Sang-Lin $\operatorname{Han}^{* * * *}$
}

\begin{abstract}
Our study is trying to investigate the perceived training effectiveness by applying the theory of planned behavior (TPB) and Technological Acceptance Model (TAM) and intend to examine the effects of individual differences on perceived training effectiveness and performance of individuals. The main purpose is to evaluate the perceived training effectiveness, and role of individual differences in terms of learning.

The results of this study supported all the hypothesis that participants with higher level of creative self-efficacy, intrinsic motivation, creativity and emotional intelligence (EI) will have greater inclinations to learn. Results showed that perceive training effectiveness is positively related to training transfer and training transfer increase the performance of individuals.

Study results significantly agree with the theory of planned behavior (TPB) which was applied to measure the perceived training effectiveness and suggest trainee's perception of usefulness, ease and benefits enhance learning dimensions of participants that make any program effective. The study has highlighted a number of issues that influence the perceived training effectiveness.
\end{abstract}

Key words: Perceived training effectiveness, emotional intelligence, individual differences, performance

\footnotetext{
* Lecturer, Institute of Management Sciences, University of Balochistan, Quetta, Pakistan (miss.malik@yahoo.com), First Author

** Institute of Management Sciences, University of Balochistan, Quetta, Pakistan (J_vash@hotmail.com)

*** Department of computer science University of Balochistan, Quetta, Pakistan (dr.t.arshad@gmail.com)

**** School of Business, Hanyang University, Seoul, Korea (slhan@hanyang.ac.kr), Corresponding Author
} 


\section{Introduction}

Training is considered as a highly skilled and professional activity. A training program is said to be effective only if it is relevant to the current and future needs of an organization or individual. It would be no exaggeration to claim that the organizations have undergone profound changes in the last decade (Punia \& Kant, 2013; Hirsch, 2001). The ecology of training has undergone drastic changes. Now it has systematic and integrated approaches that focus on organizing the resources for learning rather than for teaching. Training and development activities are always considered as the major driving force for the development of human resources (Nordhaug, 1989), and for boosting employees' competencies (Gritz, 1993).

However, most of these studies had limited focus on either the environmental characteristics or effectiveness of training with training transfer concept (e.g., Holton, 1996; Tracey, Tannenbaum, \& Kavanagh, 1995). In addition, the individual characteristics were expressed in earlier research studies with limited dimensions (Amabile, 1983; Carson, Peterson, \& Higgins, 2003; Giambra, 1989).

Furthermore, several thoeries support the learning phenomenon of individuals (Lourenço \& Jayawarna, 2011; Thayer \& Teachout, 1995). However, the most remarkable work on this aspect is learning theory of Bandura (1986) who presented the skills and behaviors pattern while the learning process continued and utilized this material for performance stock (Noe, Wilk, Mullen, \& Wanek, 2014). Hence, the performance can aslo be enhanced through the goal setting practice and this assumption was supported by the well known theory of goal setting (Locke, 1990).

Despite substantial development in the field of training transfer research, a rigorous exploratory study in academia and bureaucracy has not been undertaken(Haccoun \& Saks, 1998; Holton et al., 1997; Noe, 1999). This is the major significance of this study. Although there has been plenty of research that explored the effects of motivation to learn and training transfer (Geilen, 1996; Noe \& Schmitt, 1986). Our focus is to examin the transfer behavior with retention and application of learned knowledge and skills in academic and bureaucratic setting. Secondly, since there are very limited research where effectivness of training has been examined using the TPB concept. We have explored the link between these variables and how all these enhancethe performance. Lastly, the proposed model will further clarify the relationship between learning and transfer of knowledge at workplace thus serving as a guide for future research that could be utilized in managing the training programs more effectively. Similarly, this reaserch is an effort to provide new aspects for future reaserch and practical implication for effectively getting the benefits from training 
investements as well as increasing performance at workplace.

Consequently, the purpose of this research is to narrow the gap in the literature of training effectiveness. We will achieve this goal by identifying the effectiveness of training program, focusing specifically on perception of usefulness, benefits, ease and learning. We will discuss how the learning transfers at work and increase the performance. It was indispensable, therefore, to develop such a comprehensive model that covers the entire dimension accurately.

Training and development practices have a great significance in enhancing the economic progress of Balochistan, the most underdeveloped province of Pakistan. Unfortunately, in Balochistan even the private sector is not that much developed as desired. Nevertheless, it is hypothesized that the economic development of this province is associated with high standard performance of their employees and that can only be achieved through effective training and development practices. The results of this study would enable practitioners and researchers to evaluate the effectiveness and learning in this context.

\section{Theoretical Framework and Research Hypotheses}

This study seeks to move away all the traditionally used variables of measuring the effectiveness of trainings. Theory of planned behavior (TPB) of Ajzen (Ajzen, 1991) is based upon the intentions and perceptions of individuals to engage in a certain behavior and how their behaviors can be influenced. We used these perceptions in learning dimensions for perceived training effectiveness. Therefore, TPB is extensively used to envisage the impending behavior of individuals by means of intentions construct. In this research, subjective norms are excluded for the reason that social expectation is an external factor that gives another dimension (social aspect) to this study which cannot be measured in this limited time span. It is also evident that numerous other studies also excluded subjective norms based on TPB construct (e.g. Tarkiainen \& Sundqvist, 2005).

\subsection{Relevancy of TPB and TAM for Perceived Training Effectiveness}

TPB provides a connection between behaviors and beliefs. The idea was presented by Icek Ajzen(1985) to expand the theory of reasoned action by adding the concept of perceived behavioral control. It is considered as the most reliable predictive persuasion theory. Its application are wide spread that dispose beliefs, actions, perceptions and intentions in numerous dimensions like advertising, public relations and health.

Learning is becoming a larger part of change initiatives than before because of the variety of tools, techniques, processes, and technologies 
involved (Wilson, Lizzio, \& Ramsden, 1997). These must be used in intelligent way to reap the benefits of the change initiative. Employees learn in a variety of ways, not just in a formal classroom environment, but also through technology based learning and on the job facilitation with job aids and other tools (Kaufman \& Paula, 1997).

\subsection{Connection of learning, perceived usefulness, perceived ease, and perceived benefits in evaluation of perceived training effectiveness:}

To understand the association between learning, perceived usefulness, perceived ease and perceived benefits, we first focus on the Theory of Reasoned Action (TRA) by Ajzen and Fishbein (1980), which refers to how beliefs shape up the attitudes toward learning behavior. TAM model was based upon the TRA (Davis, 1989) and TPB. TAM suggests that using of a certain tool is based on beliefs, namely perceived usefulness and perceived ease of use. "Perceived usefulness is defined as the extent to which a person believes that using a particular technology will enhance her/his job performance, while perceived ease of use is defined as the degree to which a person believes that using a technology will be free from effort" (Venkatesh \& Davis, 2000, p.116).

These perceptions frame the learning orientation of individuals. In fact, a significant amount of literature is needed to support the notion of training effectiveness models (Kirkpatrick's, 1959; Phillips, 1997; Shepperd, 1999) and there are very few studies which used TAM in business and management world (Lourenço \& Jayawarna, 2011; Thayer \& Teachout, 1995). Therefore, there was a big need to widen the application of TAM in domain of trainings and specially in measuring the perceived training effectiveness of training.

\subsection{Individual Differences}

Diverse personalities depict different individuals and that has been considered as more efficient and functional usage to directly analyze the individuals. In the field of psychology, a diverse research has been conducted on the role of individual differences and personalities. Early research in the field of individual differences endeavors the different aspects of personality although it lacks reliable operationalization of personality variables (see Weaver, 2000), depicting inconsistent results (see, eg., Wober, 1986). Therefore, an authentic operationalization of personality traits is required. In many trait taxonomies that were used in personality research, the psychobiological model established by Eysenck and Eysenck (1985) has been widely used model in personality research, and has revealed consistent results across different samples and cultures (Barrett, Petrides, Eysenck, \& Eysenck, 1998; Eysenck \& Eysenck, 1985). 
Eysenck's model is constructed on the hierarchical organization of traits (such as creative selfefficacy, sociability, creativity, and anxiety), on which we differentiate individuals which depicts "more-or-less consistent and recurrent patterns of acting and reacting that simultaneously characterize individuals and differentiate them from others" (Costa \& McCrae, 1992). Different individuals respond differently to diverse traits differently, (Eysenck \& Eysenck, 1987), which does not mean all individual abilities can be predicted or grounded on personal traits.

We broadly differentiate individual differences on the basis of creative self-efficacy, intrinsic motivation, creativity, and EI and their role in attaining an effective training session that will increase the performance of individuals.

\subsubsection{Role of Creative self-efficacy in training effectiveness:}

Effected by the renaissance of personality research, scholars have presented the idea that creative self-efficacy is very important trait that clearly explain individual differences in terms of attitudes, behaviors, motivation and learning (e.g., Chen, Gully, Whiteman, \& Kilcullen, 2000; Judge, Locke, \& Durham, 1997). Creative self-efficacy is defined as "the belief one has the ability to produce creative outcomes" (Tierney \& Farmer, 2002, p. 1138). It is distinct from the concept of self-efficacy. Self-efficacy refers to task accomplishment belief, whereas, creative self-efficacy is a relatively development of new ideas regarding the task completion (Chen, Gully \& Eden, 2001; Judge, Thoresen, Pucik, \&Welbourne, 1999).

Thus, creative self-efficacy should be more strongly related to learning the new things or modification of existing one. Therefore, we can say that a person with high level of creative self-efficacy can find the new ideas for learning the things during training that will enhance the effectiveness of training. Thus,

Hypothesis 1: Creative self-efficacy is positively related to training effectiveness.

\subsubsection{Intrinsic motivation:}

Motivation is a theoretical construct used to explain behavior. Kanfer and Heggestad (1997) suggested that motivational aspects are the most important characteristics on which we can differentiate one individual with others. He classified these individual differences on the basis of trait and state and further distinguished them as a motivational (i.e., approach-oriented /achievement) and affective (i.e., avoidanceoriented/anxiety). Motivational individual differences refer to "the strength of motives to approach, pursue, and attain rewards or incentives." (Kanfer \& Heggestad, 1997, p. 16).

Although, in one aspect, intrinsic motivation be present within individuals, in another aspect intrinsic motivation happens in the connection 
between activities and individuals. But the resultant element of intrinsic motivation is highquality learning, especially during training if a person is intrinsically motivated then its learning capabilities will be affected in positive manner that will raise the effectiveness of training. Thus on the basis of this we hypothesized that,

Hypothesis 2: Intrinsic motivation is positively related to training effectiveness.

\subsubsection{Employee Creativity and learning:}

Creativity is defined as the fetching of novel and possibly valuable ideas (Amabile, 1996). Creativity entails a multitude of abilities and skills, comprising unique style of individual (Hennessey \& Amabile, 2010; Shalley, \& Gilson, 2004). Even though, creativity may be studied at multiple dimensions (Hennessey \& Amabile, 2010), we focused on how the creativity facilitate in developing the new ideas of learning specifically during training. Amabile's (1985) intrinsic motivation principle of creativity states that "people will be most creative when they feel motivated primarily by the interest, enjoyment, satisfaction, and challenge of the work itself, rather than by external pressures"(p.395).

Creativity also includes the refinements of existing patterns of learning, absorbing and doing things efficiently, or the discovery of productive effective procedures that help employees to raise the job performance. In addition, this will also influence other employees to take up a novel idea, apply and develop their learning to improve performance (Shalley et al., 2004). Thus we hypothesize that by using creative abilities individuals can foster more creative ways of learning new things.

Hypothesis 3: Creativity is positively related to training effectiveness.

\subsubsection{Connection of Emotional Intelligence with training effectiveness}

Emotional Intelligence is considered as the most effective factor of learning (Mayer, Salovey, Caruso \& Sitaraneos, 2003). Different research studies revealed the power of emotions, like enthusiasm or excitement, could help employees to show better customer service, accomplish their work goals, or contribute well to the organization they belong to (Austin, Saklofske, Huang, \& McKenney, 2004). Some research revealed emotions, such as excitement or enthusiasm, could stimulate employees to provide better customer service, complete their work assignments, or contribute to the organization (Ashkanasy \& Dasborough, 2003).

Elder (1997) proposes that our capabilities based on the felt emotions. Moreover, the way learner uses emotions also influences his/her capacity to learn. Therefore we can propose the following hypothesis: 
Hypothesis 4: Emotional intelligence is positively related to training effectiveness.

\subsection{Trainng transfer}

Several contemporary studies have used different models to explore training administration and revealed that effectivness of training with training transfer. For example, numerous studies with the concept of training effectivness and training transfer were rely on the sample taken out from UK based organizations (Axtell, Maitlis, \& Yearta, 1997), contrary to work of (Ismail, Hasan, \& Sulaiman, 2010) who conducted a study in Malaysia with 100 employees(with techincal background) exhibited that direct relationship in acquring new skills and knowledge with training transfer .

Research suggested that learning is not that much useful if it won't penetrate to the job. (Noe \& Ford, 1992; Souitaris, Zerbinati, \& Al Laham, 2007; Kontoghiorghes, 2004; Noe, 1999). Hence, the participants learning contribute to effectivness of that trainingif it would be transferred (Baldwin et al., 1991). Without clear identification of these aspects, training effectivness and the outcomes of training would be badly affected. Thus, we hypothesize that,

Hypothesis 5: Training effectiveness is positively related to training transfer.

\subsection{Performance}

Literature indicates the support that training transfer and performance has the positive relationship (Dastmalchian \& Blyton, 1992; Russell, Terborg \& Powers, 1985). Organizations visulize the training programs as a sort of investment that they are doing in order to enhance the knowledge skills and abilities of their emloyess for performance enhancement (Ford \& Weissbein, 1997).

A considerable theoretical frame work is available on contribution of training transfer activities to the enhancement of performance. Acquiring of latest knowledge always enhances performance of employees and this new knowledge brings innovation among employees and develops a skill that brings out the abilities how to respond change and how to use different skills at work. In the study of Russell et al. (1985), he examined retail stores discovered a substantial positive association between performance and trained work force. Effective training develops professionalism among employees and a very strong positive aptitude and multitasking skills, in addition to skill enrichment that extensively contributes towards profit generation (Pfeffer, 1998). Thus, we hypothesize that,

Hypothesis 6: Training transfer is positively related to individual performance. 
〈Figure 1〉 Conceptual Framework

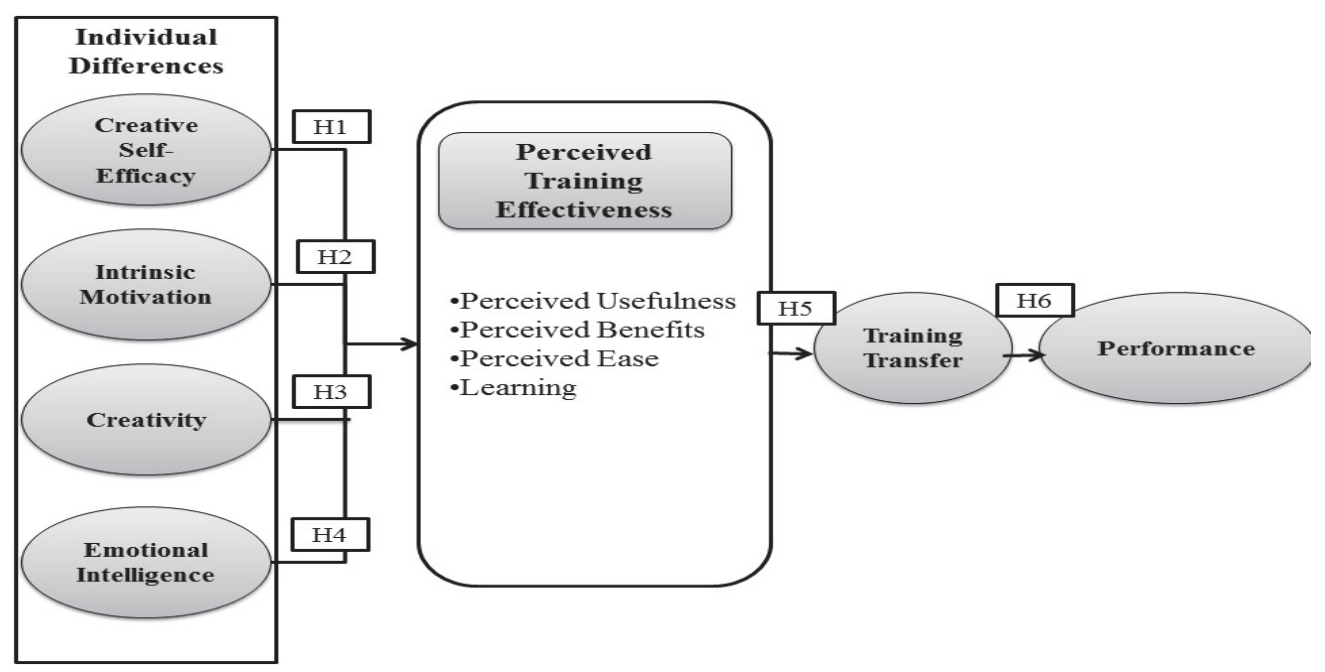

\section{Research Methodolgoy}

This study was cross-sectional design based on survey questionnaire. The objective associated with this research study was to gather information about training effectiveness, in particular, what individual differences helps in learning dimensions of individual's. Furthermore, combination of two survey types was used; Self-administered and other's rated. Collection of sample was carried out through convenience sampling method in order to get the appropriate and relevant responses for this study. Bureaucracy and academia formed the population from which the sample was drawn. Employees of Balochistan Civil Secretariat, Quetta, Pakistan and National Institute of Management (NIM), represented bureaucracy. Likewise teaching faculty of University of Balochistan (UOB) and Sardar Bahadur Khan (SBK) University represented academia. Sample was collected with all those employees who recently (past six months) attended trainings.

\subsection{Sample Selection}

Collection of sample was carried out through convenience sampling method in order to get the appropriate and relevant responses for this study. Bureaucracy and academia formed the population from which the sample was drawn. Employees of Balochistan Civil Secretariat, Quetta and National Institute of Management (NIM), represented bureaucracy. Likewise teaching faculty of University of Balochistan (UOB) and Sardar Bahadur Khan (SBK) University represented academia. 


\subsection{Measures:}

All items were measured on a five-point scale, ranging from 1 (strongly disagree) to 5(strongly agree).

\subsubsection{Creative Self-Efficacy:}

The construct creative self-efficacy was measured through the scale developed by Tierney and Farmer (2002). Sample items included "I have confidence in my ability to solve problems creatively, "I feel that I am good at generating novel/innovative ideas and the coefficients alpha for the construct was .72.

\subsubsection{Intrinsic motivation:}

Three indicators, to measure employee intrinsic motivation was adapted from the work of Amabile (1985) and Tierney et al. (1999). Basically, it measures the level of engagement in a behavior arises from within the individual. Examples of items are: "I enjoy finding solution of complex problems and I enjoy creating new procedures for work task". A higher perceived benefits score suggests higher levels of appreciation of the skills acquired through training and the coefficients alpha for the construct was.78.

\subsubsection{Creativity:}

The questionnaire created by Mueller and
Thomas (2001) was utilized for measuring the creativity based on the original Jackson Personality Inventory (1994). The variable "creativity" was operationalized by items tapping the innovativeness of the respondents. For example: "I often surprise people with my novel/innovative ideas". A higher score in creativity suggests higher levels of innovativeness and the coefficients alpha for the construct was .82 .

\subsubsection{Emotional intelligence:}

To measure the construct of EI 16 items based Wong and Law (2002) Emotional Intelligence scale (WLIIS) was adopted. The Cronbach alpha value was .90.

\subsubsection{Perceived usefulness:}

Five items were adopted from scale developed by Davis (1989) to measure the Perceived usefulness. This scale consists of 5 items. Examples of item is 'Using the 'skills' introduced in the training will improve my work performance" and the coefficients alpha for the construct was .83.

\subsubsection{Perceived Ease:}

Three items based construct of Perceived ease was adopted from Davis (1989). Examples of items are "Learning to use the 'skills' introduced in the training would be easy for 
me”. A higher perceived ease score suggests higher levels of chances of the skills acquired through training and the coefficients alpha for the construct was .65 .

\subsubsection{Perceived Benefits:}

Five indicators, four from Noe and Schmitt (1986) and one from Davis (1989), were adapted to measure perceived benefits, for example: 'I do not know the benefits that can be derived by mastering the skills introduced in the training' (reverse-scored). A higher perceived benefits score suggests higher levels of appreciation of the skills acquired through training and the coefficients alpha for the construct was .85 ".

\subsubsection{Learning:}

Construct of learning was adopted from the "course experience questionnaire" (Wilson et al., 1997) to measure the "learning which holds the idea of trainee's perception of the effects of the training on his/her acquisition of new insights" (Velada \& Caetano, 2007, p. 287). Example of items is "This course/training has helped me to develop the ability to plan my own work". The Coefficients alpha for current study was .72 .

\subsubsection{Transfer of Training:}

Scale for training transfer was adopted transfer of training scale from Xiao (1996). Transfer of training was measured in the concept of attainment, effectiveness and withholding of learned material in the job and it was measured by the application of KSA through self-perceived productivity efficiency. Examples of item is "I can accomplish job tasks better by using new KSA". In the study of Xiao (1996) the reliability coefficient was.83. In the field of basic research, a reliability of .70 or higher supposed to be sufficient (Nunnally, 1978). The Coefficients alpha for current study was .78.

\subsubsection{Job Performance}

Job performance was measured through the scale developed by Tett et al. (2000). performance was measured through others rated criteria. Performance was measured into two broad dimensions; task performance and contextual performance. Coefficient alphas for the task and contextual behavior were .94 and .93 respectively.

\section{Analyses of Data:}

The tests that were performed comprised "missing data analysis", outliers, linearity, and "normality", Meeting these assumptions, shows validated and unbiased results (Hair et al., 2006). After validation of the assumptions of 
multivariate, exploratory factor analysis (EFA) and Confirmatory Factor Analysis (CFA) were performed to assess the factorial structure of the scales. Structural equation modeling (SEM) based on maximum likelihood method was then used to test the proposed hypothesized model (Arbuckle, 2007).

\subsection{Normality of data}

Normality of data was tested. Refereeing to their suggestions, using likelihood estimation skewness and kurtosis of variables from -3 to +3 , is acceptable (Muthén \& Kaplan, 1985).

The Mahalanobis distance was used to check the presence of outliers in the dataset. In all observations of data set, Mahalanobis distance has the values (0-2). It meets the recommended criteria (Field, 2009); representing outliers has no impact on subsequent analysis (Field, 2009).

All items inter correlated with each other significantly. Skewness and kurtosis values for all values were well within acceptable range $(-3.0$ to +3.0$)$

EFA results indicated one factor solution. All items loaded on a single factor). KMO values were well within acceptable range. Bartlett's Test of Sphericity was significant, $h^{2}$ values were well above the acceptable value ( $>.50)$. EFA results indicated one factor solution. All items loaded on a single factor ( $\%$ of variance $=59.65)$. KMO values were well within acceptable range. Bartlett's Test of Sphericity was significant, $\mathrm{h}^{2}$ values were well above the acceptable value ( > .50).

\subsection{Confirmatory factor analysis (CFA):}

CFA is a confirmatory technique. At this point, the researcher has a concrete knowledge regarding the number of factors, the relationship among these factors, and the relationship between the measured variables and factors. In a CFA the objective is to test the hypothesized structure. According to Ullman (2006).

The hypothesized CFA model offers the fundamental structure for the estimated population covariance matrix. The model data fits were calculated through these indices: the Comparative Fit Index(CFI: >.90 satisfactory, > .95 excellent) (Andersen \& Glaser, 2002; Bentler \& Bonett, 1980: Browne, MacCallum\& Kim, 2002); the relative discrepancy index (CMIN/df; a value of 3 or lesser denotes a good fit); The Normed Fit Index (NFI; > .90 satisfactory, $>.95$ excellent) (Kaplan, 2000), and the Root Mean Square Error of approximation (RMSEA; $<.08$ acceptable, $<.05$ excellent)( Brown \& Cudeck, 1993).

A sample size of 204 was used for the study. Structural Equation Modeling (SEM) experts propose that samples of more than 100 (per sample) can better show accurate results (e.g., Arbuckle, 2007; Bollen, 1989; Browne et al., 2002: Dukerich, Golden, \& Shortell, 2002; Gignac, 2006: Golden, Dukerich, \& Fabian, 2000). This fit index was used in many structural equation 
modelling studies (Dukerich et al., 2002; Golden et al., 2000; Young-Ybarra, \& Wiersema, 1999). Since, it was not possible to perform CFA analysis for 3 item scales (Kline, 2011), we relied on exploratory factor analysis results. All the Fit indices indicated acceptable data model fit.

All items loaded significantly on the latent factors. Fit indices indicated acceptable data model fit. Latent Variables (Scales) revealed to be strongly correlated with each other. In Subsequent Analysis we used the composite scores, average of all scales (EFFICACY, INT, CREAT, \&EI).

All items loaded significantly on the latent factors. Fit indices indicated acceptable data model fit. Latent Variables (Scales) revealed to be strongly correlated with each other.

Creative self-efficacy is significantly correlated with intrinsic motivation $(r=.39, p<.01)$; intrinsic motivation is significantly correlated with creativity $(r=.64, p<.01)$ and similarly, creativity has significant relationship with EI $(r=.68, p<.01)$. Results also shows that all the indicators of perceived training effectiveness (perceived usefulness, perceived benefits, perceived ease and learning) are positively correlated with each other simultaneously $(r=.81, p<$ $.01, r=.64, p<.01, r=.67 ; p<.01)$. Likewise training transfer has a significant relationship with task performance $(r=.72, p<.01)$. Results also demonstrated the significant positive relationship among task and contextual performance $(r=.85, p<.01)$.

All items loaded significantly on the latent factors. Fit indices indicated acceptable data model fit. Latent Variables (Scales) revealed to be strongly correlated with each other.

One of the purposes of this study was to test if individual differences helped in learning dimensions of individuals; perceived training effectiveness increased the level of transfer of training and high level of training transfer improved the performance of individuals. We tested a theoretical model with latent variable of perceived training effectiveness with four indicator variables (Perceived Benefits, Perceived usefulness, Perceived Ease, and Learning) predicting perceived training effectiveness. Latent variable individual difference had four

〈Table 1〉 Fit indices for CFA of Perceived Training Effectiveness.

\begin{tabular}{cccccccc}
\hline $\mathrm{X}^{2}$ & $\mathrm{df}$ & $\mathrm{X}^{2} / \mathrm{df}$ & $\mathrm{sig}$ & CFI & TLI & NFI & RMSEA \\
\hline 231.84 & 46 & 1.58 & .00 & .95 & .94 & .87 & $.05(.04,067)$ \\
\hline
\end{tabular}

〈Table 2〉 Fit indices for CFA of Research model.

\begin{tabular}{cccccccc}
\hline$\chi^{2}$ & Df & $\chi^{2} / \mathrm{df}$ & sig & CFI & TLI & NFI & RMSEA \\
\hline 764.723 & 292 & 2.61 & .000 & .87 & .85 & .87 & $.08(.08, .09)$ \\
\hline
\end{tabular}


indicator variables (creative self-efficacy, intrinsic motivation, creativity and EI).

The model did not fit to the data $x^{2}=$ 764.723, $\mathrm{df}=292, \mathrm{x}^{2} / \mathrm{df}=2.61$, sig $=.000$, $\mathrm{CFI}=.87$, TLI $=.85, \mathrm{NFI}=.87$ and RMSEA $=.08)$. The fit is near to acceptable range, but it might be improved. We revised our estimation by examine the largest modification.

These indices make suggestions about loosening certain model parameters in order to improve the overall model fit. As long as any decisions made on the basis of modification indices are theoretically meaningful and do not result in an unidentified model they can be helpful in improving model specification.

Individuals will absolutely respond to the external elements by self-managing their psychological cognitive elements (e.g. creative self-efficacy; intrinsic motivation; and EI), which eventually shape up the behaviors of individuals. This reflection specifies that in due course, creativity should be originated by the individuals themselves with the means of specific psychosomatic cognition procedures. Different scholars have specified that creative self-efficacy, and intrinsic motivation, are the main cognitive tools to drive creativity of individuals (Gong, Huang \& Farh, 2009). Choi (2004) specified that confidence of individuals in understanding the emotions, motivation to generate novel ideas and creative abilities are the significant psychological cognitive elements in creativity.
Creative self-efficacy is based upon the strongest belief about oneself for the possession of creative ideas to perform differently. Moreover, conferring to Amabile (1983, 1988), whose system approach is quite significant in the creativity research, which is based upon creativityrelevant skills, task motivation and domainrelevant skills. We focused that how the intrinsic motivation contributes to a person to be creative. Thus, our approach aligns with Amabile's (1988) theoretical framework (e33 $\leftrightarrow$ e35).

Intrinsic motivation operationalizes an individual to be creative. It has been made known to clearly relate to creativity (Tierney \& Farmer, 2002: 2004). Whereas, this notion seems to be a reality that the internal driving force push them to learn and understand things differently. Hence, the more the level of the intrinsic motivation, the more innovative outcomes are to be expected. In this case it is consider as the "internal-push" that originate within the individual and nurture a creative individual (e33 $\leftrightarrow \mathrm{e} 34)$

Nonetheless, the phenomenon of creativity is rather subtle and certain factors stimulate thinking and learning process. De Bono (1986) proposes that an individual may involve in many different thoughts: information, emotions, hope, creativity and logic. Adams (1986) suggests that among different individuals switch of thinking occurs; from negative judgment to a creative process. This is evident that recognition of creativity through emotional intelligence is 
possible. Thus, they response differently according to their emotional intelligence level (e33 $\leftrightarrow \mathrm{e} 32)$.

\subsection{Test Revised Measurement Model:}

The new estimated model had acceptable fit to the data $x^{2}=597.287, \mathrm{df}=290, \mathrm{x}^{2} / \mathrm{df}=$ 2.06, sig $=.000, \mathrm{CFI}=.91, \mathrm{TLI}=.90, \mathrm{NFI}=$ .90 and RMSEA $=.07$.

Perceived usefulness was the strongest predictor of perceived training effectiveness (.77), Perceived benefits also predicted perceived training effectiveness positively (.85), Perceived ease was predictive of higher perceived training effectiveness (.65), and learning also predicts perceived training effectiveness (.77).

Creative self-efficacy, intrinsic motivation, creativity and EI were the predictor of latent variable of perceived training effectiveness (.20, .36, .66 and .21, respectively), whereas perceived training effectiveness were strongly related to training transfer (.98). Moreover, training transfer were directly related to performance (.75). The strongest predictor of performance was task performance (.93) and contextual performance also predict the job performance well (.85).

The standardized path estimates indicate that all hypothesized relationships between the seven constructs were significant at the minimum of $\mathrm{p} \leq .001$ level)

In the structural model the individual paths were examined using the standardized parameter estimates. As proposed in H1, creative selfefficacy is positively related to perceived training effectiveness. Thus our first hypothesis was supported as a significant parameter estimate $(\beta=.20, p<.001)$. H2 was supported, as a statistically significant parameter estimate was found for the path between intrinsic motivation to perceived training effectiveness ( $\beta=0.36$, $p<.001)$. Our third hypothesis proposes the positive role of creativity in perceived training effectiveness and positive parameter estimate was found for the path from creativity to perceived training effectiveness $(\beta=.66, p<$ .001) provided support for H3. A hypothesized relationship between the EI and perceived training effectiveness was received the statistical support $(\beta=.21, p<.001)$ for $\mathrm{H} 4$. In relation to $\mathrm{H} 5$, a significant relationship was found between the perceived training effectiveness and training transfer $(\beta=.98, p<.001)$. However, the statistically significant parameter estimate ( $\beta=.75, p<.001)$ for the relationship between training transfer and performance indicated support for H6. In comparison of the magnitudes of the coefficient scores, creativity received the highest statistical support to argue that, it is the most significant factor of individual differences that cause a significant in perceived training effectiveness $(\beta=.66, p>.001)$. However, the most positive and highest loadings were found for the perceived training benefit ( $\beta=$ $.85, p>.001$ ), considering as a strong indicator of perceived training effectiveness. As our H5 
suggest a positive relationship between perceived training effectiveness and training transfer ( $\beta=.98, p<.001)$ received one of the highest standardized value.

\section{Conclusions and Discussions}

Although training and development has received a lot of attention these days, more research is needed to elucidate the impact of individual differences on effectiveness of training and development practices and how the effective training enhances the performance. Specifically, there is a dire need to address effectiveness with new dimensions beyond all those traditional model discussed earlier (Lourenco \& Jayawarna, 2010; Ajzen, 1991). The main objective of this study is to address the effectiveness of training by using the TPB and their connection with individual differences and performance. It offers concrete discussion around the learning behavior with individual differences. It also provides the insight about the explicit associations between individual differences and effectiveness of training including training transfer. Our first hypothesis (H1) was that creative self-efficacy is positively related to perceived training effectiveness. The results of this study showed positive relationship between creative self-efficacy and perceived training effectiveness. In individual differences creativity is one of the most important dimensions that provide the basis of differences. In summary, many studies have addressed creative selfefficacy as a major individual difference in the field of training research (Robert, Bostrom, Lorne, \& Maung, 1990; Sun, Tsai, Finger, Chen, \&Yeh, 2008). People with high level of self-efficacy are more likely than those with low self-efficacy to develop effective task and learning strategies (Latham, Winters, \& Locke, 1994; Wood \& Bandura, 1989). Our findings support the propositions that creative selfefficacy influences trainees to be creative in their task and assignments (Ford, 1996).

Our second hypothesis (H2) was "intrinsic motivation is positively related to perceived training effectiveness". The results of this study showed positive association between intrinsic motivation and perceived training effectiveness. These results are consistent with Noe (1986), who integrated motivational and situational factors derived from organizational behavior theory into the research model. He proved that trainees' attributes and motivational attitudes towards training influence their perceived effectiveness of training. These results are consistent with the study of Facteau et al. (1995) where he demonstrated that trainees who perceived intrinsic reasons to attend training stated higher levels of motivation to learn and attend.

Our third hypothesis (H3) was "creativity is positively related to perceived training effectiveness". 
The results of this study showed a positive relation between creativity and perceived training effectiveness. The literature showed that (with reference to learning) creativity is an imperative component, in finding the new ways of doing and learning things differently (Amabile, 1996; Amabile et al., 2005; Corbett, 2005; DeTienne\& Chandler, 2004; Dimov, 2007; Rae, 2007; Ward, 2004). A creative person has the ability to understand and retain things differently (Lourenco \& Jayawarna, 2010), which is a very helpful tool in learning activities (Tennant, 1999).

Our fourth hypothesis (H4) was "EI is positively related to perceived training effectiveness". The results of this study showed a positive relation between EI and perceived training effectiveness. Findings of this study are consistent with the findings of DeTienne and Chandler (2004) who suggested that numerous attributes, set of behaviors, and abilities among trainees will not be similar and consequently the training's effect will alter accordingly.

Our fifth hypothesis (H5) was "Perceived training effectiveness is positively related to training transfer". The results of this study showed a positive relation between perceived training effectiveness and training transfer. As hypothesized, a strong relationship was found between perceived training effectiveness and the transfer of learned material to the work settings. Our research also explores one dimension of theory of planned behavior (TPB) that considered personal norms, beliefs and role of perceptions in learning process. The results indicate that when a person perceives something more beneficial and more easy to use, his/her learning will improve which ultimately enhances the effectiveness of trainings and will increase the chances to transfer it at workplace. Hence, perceived training effectiveness increases the chances of training transfer.

Our Sixth hypothesis (H6) was "Training transfer is positively related to performance". The results of this study showed a positive relation between training transfer and performance. This is in line with the study of (Nassazi, 2013) where he proved training transfer is the biggest predictor of performance.

The measure of training effectiveness indicated a good fit (TLI .94; CFI; .94; $\mathrm{x}^{2} / \mathrm{df}, 5.45$; and RMSEA, .05). The development of an effective training model for the field of training and development was a significant component of this research. It was significant to present a model that "fits" well and also consistent with contemporary literature and former research. This model and all variables measuring training effectiveness, individual differences and performance are in line with current literature and previous research.

From the results, it is also revealed that training is one of the most valuable tools for the enhancement of performance (e.g. Kozlowski \& Hults, 1987) and it should be supplemented by perceived usefulness and other motivation 
policies that will help in training transfer. The lack of proper research in the field of individual differences play a vital role in the learning process during training sessions.

\subsection{Managerial Implications}

One of the most exclusive contributions of this study is that it measures the training effectiveness in different context with the antecedent of individual differences and consequences of task and contextual performance. An assessment of training effectiveness has not been systematically performed earlier because of absence of analysis of these variables.

Even though the current study made an effort to further examine whether individual differences make any difference in perception of learning and if training is properly transferred and whether it improves the task and contextual performance of employees.

This study will help the practitioners, especially people from the academia and bureaucracy, to improve their quality of trainings. This study is also worthwhile because the sample was taken from Balochistan which is proven as the most deprived province of Pakistan. Whereas, effective training programs can enrich the human resource development of Balochistan by implementing the measures explained in the study.

Moreover, the results suggest that an individual's creative self-efficacy helps in learning (H1).
Likewise, intrinsic motivation and creativity help the individuals to perceive introduced skills as more beneficial that support our hypothesis 2 and 3 respectively. This study helps in recognizing the patterns of emotional transitions that may help individuals to learn things more effectively, which may in turn allow them to better understand the skills and behaviors (Mayer \& Salovey 1997) training effectiveness (hypothesis 4). Hence, if training is performed effectively then it strengthens the concept of training transfer ; the positive relationship found between training effectiveness and training transfer (hypothesis 5); The power of our perception of usefulness and benefits, that enhance the effectiveness of training also established in TPB based studies (Cordano \& Frieze, 2000; Lim \& Morris, 2004).

\subsection{Limitation and Future Directions}

The results may be affected by the law and order situation of Balochistan and especially Quetta as this region is one of the centers of the war against terrorism. It might be possible that individual differences or task and contextual performance rate may differ due to environmental conditions.

Using these organizational characteristics may provide meaningful perspectives for understanding how organizational culture, climate and nature affect training transfer and performance. The direction of causality cannot be established in 
cross sectional study and will have to be tested using longitudinal data (Aryee, Budhwar, \& Chen, 2002). The results of this study depend on the sample taken from academia and bureaucracy. In order to completely recognize the effect of training and development activities on job performance, more organizations in various sectors need to be used in future study. Although learning is a creative process but the application of learning also require creativity. Likewise, EI of instructor is also very important aspect and these avenues can be further explored in future research.

Finally, some other individual differences like age, gender and educational level should be considered in future research because they are given considerable attention in the recent training and development literature (Ismail et al., 2010; Tai, 2006; Tsai \& Tai, 2003). The importance of these issues needs to be further explained in future research.

〈Received August 28. 2017〉

〈Accepted November 1. 2017〉

\section{References}

Amabile, T. M. (1983). The social psychology of creativity: A componential conceptualization. Journal of Personality and Social Psychology, 45: 357-376.

Amabile, T. M. (1985). Motivation and creativity:
Effects of motivational orientation on creative writers. Journal of personality and social psychology, 48(2), 393-399

Amabile, T. M. (1988). A model of creativity and innovations in organizations. In B. M. Staw \& L. L. Cummings (Eds.), Research in organizational behavior (pp. 123-167). Greenwich, CT: JAI Press.

Amabile, T. M. (1996). Creativity in context. Boulder, CO: Westview.

Amabile, T. M., Barsade, S. G., Mueller, J. S., \& Staw, B. M. (2005). Affect and creativity at work. Administrative science quarterly, 50(3), 367-403.

Ajzen, I. (1991). The theory of planned behavior. Organizational behavior and human decision processes, 50(2), 179-211.

Ajzen, I. (1985). From intentions to actions: A theory of planned behavior. In J. Kuhl \& J. Beckman (Eds.), Action-control: From cognition to behavior (pp. 11-39). Heidelberg: Springer.

Ajzen, I., Fishbein, M. (1980). Understanding attitudes and predicting social behavior. Englewood Cliffs, NJ: Prentice-Hall.

Ashkanasy, N. M., \& Dasborough, M. T. (2003). Emotional awareness and emotional intelligence in leadership teaching. Journal of Education for Business, 79(1), 18-22.

Austin, E. J., Saklofske, D. H., Huang, S. H. S., \& McKenney, D (2004). Measurement of trait emotional intelligence: Testing and cross-validating a modified version of 
Schutte et al.'s (1998) measure. Personality and Individual Differences, 36, 555-562.

Axtell, C. M., Maitlis, S., \& Yearta, S. K. (1997). Predicting immediate and longerterm transfer of training. Personnel Review, 26(3), 201-213.

Baldwin, T. T., \& Ford,. J. K. (1988). Transfer of training: A review and directions for future research. Personnel Psychology, 41 (1) $63-105$.

Baldwin, T. T., Magjuka, R. J., \& Loher, B. T. (1991). The perils of participation: Effects of choice of training on trainee motivation and learning. Personnel Psychology, 44(1), 51-65.

Bandura A. (1986). Social Foundations of Thought and Action: A Social Cognitive Theory. Englewood Cliffs, NJ: PrenticeHall.

Barrett, P. T., Petrides, K. V., Eysenck, S. B. G., \& Eysenck, H. J. (1998). The Eysenck personality Questionnaire: An Examination of the factorial similarity of $\mathrm{P}, \mathrm{E}, \mathrm{N}$, and Lacross 34 countries. Personality and Individual Differences, 25, 805-819.

Boudreau, J. W., Boswell, W. R., \& Judge, T. A. (2001). Effects of personality on executive career success in the United States and Europe. Journal of Vocational Behavior, 58(1), 53-81.

Blume, B. D., Ford, J. K., Baldwin, T. T., \& Huang, J. L. (2010). Transfer of training: A meta-analytic review. Journal of
Management, 36(4), 1065-1105.

Cheng, E. W. L., \& Ho, D. C. K. (2001). A review of transfer of training studies in the past decade. Personnel Review, 30, $102-118$.

Choi, J. N. (2004). Individual and contextual predictors of creative performance: The mediating role of psychological processes. Creativity Research Journal, 16(2-3), 187199.

Corbett, A. C. (2005). Experiential learning within the process of opportunity identification and exploitation. Entrepreneurship Theory and Practice, 29(4), 473-491.

Cordano, M., \& Frieze, I. H. (2000). Pollution reduction preferences of US environmental managers: Applying Ajzen's theory of planned behavior. Academy of Management Journal, 43(4), 627-641.

Costa, P. T. \& McCrae, R. R. (1992). An introduction to the Five-Factor model and its Applications. Journal of Personality, 60, 175-215.

Dastmalchian, A., \& Blyton, P. (1992). Organizational structure, human resource practices and industrial relations. Personnel Review, 21(1), 58-67.

Davis, F. D. (1989). Perceived usefulness, perceived ease of use, and user acceptance of information technology. MIS Quarterly, 13(3) : 319-340.

DeTienne, D. R., \& Chandler, G. N. (2004). Opportunity identification and its role in 
the entrepreneurial classroom: A pedagogical approach and empirical test. Academy of Management Learning \& Education, 3 (3), 242-257.

Dimov, D. (2007). From opportunity insight to opportunity intention: The importance of person-situation learning match. Entrepreneurship Theory and Practice, 31 (4), 561-583.

Elder, L. (1997). Critical Thinking: The Key to Emotional Intelligence. Journal of developmental education, 21(1), 40-41.

Eysenck, H. J. \& Eysenck, M. W. (1985). Personality and Individual Differences: a natural science approach. Plenum Press, New York.

Eysenck, H. J., \& Eysenck, M. W. (1987). Personality and individual differences. Plenum.

Facteau, J. D., Dobbins, G. H., Russell, J. E., Ladd, R. T., \& Kudisch, J. D. (1995). The influence of general perceptions of the training environment on pretraining motivation and perceived training transfer. Journal of management, 21(1), 1-25.

Ford, J. K., \& Weissbein, D. A. (1997). Transfer of training: An updated review and analysis. Performance improvement quarterly, 10(2), 22-41.

Ford, D. Y. (1996). Reversing underachievement among gifted Black students. New York: Teacher's College Press Information Systems, $1(1), 8$.
Geilen, E. W. (1996). Transfer of training in corporate setting: testing a mode. In Proceedings of the 1996 Academy of Human Resource Development Annual Conference (pp. 434-441). Academy of Human Resource Development.

Giambra, L.M. (1989). Task-unrelated-thought frequency as a function of age: A laboratory study. Psychology and Aging, 4, 136-143.

Gong, Y., Huang, J. C., \& Farh, J. L. (2009). Employee learning orientation, transformational leadership, and employee creativity: The mediating role of employee creative selfefficacy. Academy of Management Journal, 52(4), 765-77.

Goleman, D. (1995). Emotional Intelligence. New York, NY: Bantam Books.

Gritz, R. M. (1993). The impact of training on the frequency and duration of employment. Journal of Econometrics, 57(1), 21-51.

Haccoun, R. R., \& Saks, A. M. (1998). Training in the 21st century: Some lessons from the last one. Canadian Psychology/Psychologie canadienne, 39(1-2), 33.

Hair, J. F., Tatham, R. L., Anderson, R. E., \& Black, W. (2006). Multivariate data analysis (Vol. 6). Upper Saddle River, NJ: Pearson Prentice Hall.

Hennessey, B. A., \&Amabile, T. M. (2010). Creativity. Annual Review of Psychology, 61, 569-598.

Richman-Hirsch, W. L. (2001). Post-training 
interventions to enhance transfer: the moderating effects of work environments. Human Resource Development Quarterly, 12 (2) 105-120.

Holton, E. F. III, Bates, R., Seyler, D., \& Carvalho, M. (1997). Toward construct validation of a transfer climate instrument. Human Resource Development Quarterly, 8, 95-113.

Holton, E. F. (1996). The flawed four-level evaluation model. Human Resource Development Quarterly, 7(2), 5-21.

Hoyle, R. H. (Ed.). (1995). Structural equation modeling: Concepts, issues, and applications. Sage Publications.

Ismail, A., Hasan, A. B. M., \& Sulaiman, A. Z. (2010). Supervisor's role as an antecedent of training transfer and motivation to learn in training programs. Acta Universitatis Danubius.Economica, 6(2).

Jackson, D. N. (1976). Jackson Personality Inventory Manual. Port Huron, MI: Research Psychologists Press.

Judge, T. A., Locke, E. A., \& Durham, C. C. (1997). The dispositional causes of job satisfaction: A core evaluations approach. Research in Organizational Behavior, 19, 151-188.

Judge, T. A., Thoresen, C. J., Pucik, V., \& Welbourne, T. M. (1999). Managerial coping with organizational change: A dispositional perspective. Journal of applied psychology, 84(1), 107.
Kahn, H., \& Wiener, A. J. (1969). The year 2000. Macmillan.

Kanfer, R., \& Heggestad, E. D. (1997). Motivational traits and skills: A personcentered approach to work motivation. Research in Organizational Behavior, 19, $1-56$.

Kaufman, R. S., \& Paula, M. (1997). The guidebook for Performance Improvement: Working with individuals and Organization. San Fransisco: Jossey-Bass Pfeiffer.

Kozlowski, S. W., \& Hults, B. M. (1987). An exploration of climates for technical updating and performance. Personnel Psychology, 40(3), 539-563.

Lourenço, F., \& Jayawarna, D. (2011). Enterprise education: the effect of creativity on training outcomes. International Journal of Entrepreneurial Behavior \& Research, 17 (3), 224-244.

Mayer, J. D., \& Salovey, P. (1997). What is emotional intelligence? In P. Salovey \& D. J. Sluyter (Eds.), Emotional development and emotional intelligence: Educational implications (pp. 3-31). New York: Basic Books.

Mayer, J. D., Salovey, P., Caruso, D. R., \& Sitaraneos, G. (2003). Measuring emotional Intelligence with the MSCEIT V2.0. Emotion, 3, 97-105.

Mednick, S. A. (1962). The associative basis of the creative process. Psychological Review, 69, 220-232. 
Mueller, S. L., \& Thomas, A. S. (2001). Culture and entrepreneurial potential: A nine country study of locus of control and innovativeness. Journal of business venturing, 16(1), 51-75.

Nassazi, A. (2013). Effects of Training on Employee Performance: Evidence from Uganda.

Noe, R. A., Wilk, S. L., Mullen, E. J., \& Wanek, J. E. (2014). Employee Development: Issues in Construct Definition and Investigation of Antecedents. Improving Training Effectiveness in Work Organizations, ed. JK Ford, SWJ Kozlowski, K. Kraiger, E. Salas, and MS Teach out (Mahwah, NJ: Lawrence Erlbaum, 1997), 153-89.

Noe, C. F. (1999). Voluntary disclosures and insider transactions. Journal of Accounting and Economics, 27(3), 305-326.

Noe, R. A., \& Ford, J. K. (1992). Emerging issues and new directions for training research. Research in personnel and human resources management, 10, 345-384.

Noe, R. A., \& Schmitt, N. (1986). The influence of trainee attitudes on training effectiveness: Test of a model. Personnel Psychology, 39, 497-523.

Pfeffer, J. (1998). The Human Equation: Building Profits by Putting People First. Harvard Business School Press, Boston, MA.

Phillips, J. (1997). Handbook of Training Evaluation and Measurement Methods. Houston: Gulf, Texas.
Punia, B. K., \& Kant, S. (2013). A Review of Factors Affecting Training Effectiveness vis-à-vis Managerial Implications and Future Research Directions. International Journal of Advanced Research in Management and Social Sciences, 2(1), 151-164.

Ryan, R. M., \& Deci, E. L. (2000). Selfdetermination theory and the facilitation of intrinsic motivation, social development, and well-being. American psychologist, 55 (1), 68.

Russell, J., Terborg, J., \& Powers, M. (1985). Organizational performance and organizational level training and support. Personnel Psychology, 38, 849-863.

Shalley, C. E., \& Gilson, L. L. 2004. What leaders need to know: A review of social and Contextual factors that can foster or hinder creativity. Leadership Quarterly, 15: 33-53.

Schwarz, N. (1990). Feelings as information: Informational and affective functions of affective states. In E. T. Higgins \& R. M. Sorrentino (Eds.). Handbook of motivation Emotional Intelligence: The Most Potent Factor of Job Performance and cognition: Foundations of social behavior (Vol. 2, pp. 527-561). New York: Guil.

Shepherd, C. (1999). Assessing the ROI of Training. www.fastrak-conculting.com.uk. Souitaris, V., Zerbinati, S., \& Al-Laham, A. (2007). Do entrepreneurship programmes raise entrepreneurial intention of science 
and engineering students? The effect of learning, inspiration and resources. Journal of Business Venturing, 22(4), 566-591.

Tai, W. T. (2006). "Effects of training framing general self-efficacy and training motivation on trainees' training effectiveness," Personnel Review, 35(1), 51-65.

Tarkiainen, A., \& Sundqvist, S. (2005). Subjective norms, attitudes and intentions of Finnish consumers in buying organic food. British food journal, 107(11), 808822.

Tennant, M. (1999). Is learning transferable? Understanding learning at work, 165.

Tett, R. P., Guterman, H. A., Bleier, A., \& Murphy, P. J. (2000). Development and content validation of a "hyper dimensional" taxonomy of managerial competence. Human Performance, 13, 205-251.

Tierney, P., Farmer, S. M., \& Graen, G. B. (1999). An examination of leadership and employee creativity: The relevance of traits and relationships. Personnel Psychology, 52(3), 591-620.

Tierney, P., \& Farmer, S. M. (2002). Creative self-efficacy: Its potential antecedents and relationship to creative performance. Academy of Management Journal, 45, 1137-1148.

Tierney, P., \& Farmer, S. M. (2004). The Pygmalion process and employee creativity. Journal of Management, 30, 413-432.

Tracey, J. B., Tannenbaum, S. I., \& Kavanagh,
M. J. (1995). Applying trained skills on the job: the importance of the work environment. Journal of Applied Psychology, 80(2), 239-52.

Tsai, W. C., \& Tai, W. T. (2003). Perceived importance as a mediator of the relationship between training assignment and training motivation. Personnel Review, 32(2), 151163.

Velada, R., Caetano, A., Michel, J. W., Lyons, B. D., \& Kavanagh, M. J. (2007). The effects of training design, individual characteristics and work environment on transfer of training. International Journal of Training and Development, 11(4), 282294.

Ward, T. B. (2004). Cognition, creativity, and entrepreneurship. Journal of business venturing; 19(2), 173-188.

Weaver, J. B. (2000). Personality and entertainment preferences. In D. Zillmann \& P. Vorderer (Eds.), Media entertainment: The psychology of its appeal (pp. 235-247). Mahwah, NJ: Lawrence Erlbaum.

Wilson, K. L., Lizzio, A., \& Ramsden, P. (1997). The development, validation and application of the Course Experience Questionnaire. Studies in higher education, 22(1), 33-53. Wober, J. M. (1986). The lenses of television and the prism of personality. In J. Bryant \& D. Zillmann (Eds.), Perspectives on media effects (pp. 205-228). Hillsdale, NJ: Lawrence Erlbaum Associates. 
Wong, C., \& Law, K. S. (2002). The effect of leader and follower emotional intelligence on performance and attitude: An exploratory study. Leadership Quarterly, 23, 243-274.
Wood, R., \& Bandura, A. (1989). Social cognitive theory of organizational management. Academy of management Review, 14(3), 361-384. 